\title{
Functional Polymorphism in the Neuropeptide Y Gene Promoter (rs16147) Is Associated with Serum Leptin Levels and Waist-Hip Ratio in Women
}

\author{
Jochen Mutschler ${ }^{a, m}$ Elvira Abbruzzese ${ }^{m} \quad$ Klaus Wiedemann $^{b}$ \\ Christoph von der Goltz ${ }^{a} \quad$ Christina Dinter $^{a} \quad$ Arian Mobascher $^{c} \quad$ Holger Thiele $^{d}$ \\ Amalia Diaz-Lacava ${ }^{\mathrm{e}}$ Norbert Dahmen ${ }^{\mathrm{c}}$ Jürgen Gallinat ${ }^{\mathrm{i}}$ Tomislav Majic ${ }^{\mathrm{i}}$ \\ Nadine Petrovsky ${ }^{\text {h }}$ Norbert Thueraufj Johannes Kornhuberj Gerhard Gründerk \\ Lena Rademacherk Juergen Brinkmeyer' Thomas Wienker ${ }^{f} \quad$ Michael Wagnerg \\ Georg Winterer $^{d}$ Falk Kiefer ${ }^{a}$ \\ ${ }^{a}$ Department of Addictive Behavior and Addiction Medicine, Central Institute of Mental Health, University of \\ Heidelberg, Mannheim, ${ }^{b}$ Department of Psychiatry, University of Hamburg, Hamburg, ' Department of Psychiatry, \\ Johannes Gutenberg University, Mainz, ${ }^{\mathrm{d} C}$ Cologne Center for Genomics, University of Cologne, ${ }^{\mathrm{e}}$ German Center for

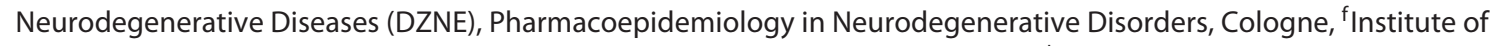 \\ Medical Biometry, Informatics and Epidemiology, ${ }^{9}$ Department of Psychiatry and ${ }^{\mathrm{h}}$ Institute of Psychology, \\ University of Bonn, Bonn, 'Department of Psychiatry, Charité University Hospital, Berlin, 'jDepartment of Psychiatry, \\ Friedrich Alexander University of Erlangen Nuremberg, Erlangen, ${ }^{k}$ Department of Psychiatry and Psychotherapy, \\ Medical Faculty, RWTH Aachen University, Aachen, and 'Department of Psychiatry, Heinrich Heine University, \\ Düsseldorf, Germany; ${ }^{m}$ Department of Psychiatry, Psychotherapy and Psychosomatics, Zürich University Hospital for \\ Psychiatry, Zurich, Switzerland
}

\section{Key Words}

Neuropeptide-Y · Polymorphism · Obesity · Waist-to-hip ratio $\cdot$ Genetics $\cdot$ rs $16147 \cdot$ Leptin

\begin{abstract}
Objective: The neuropeptide-Y (NP-Y) gene is a strong candidate gene in the pathophysiology of obesity-linked behavior, and several single-nucleotide polymorphisms of NP-Y have already been linked to body weight and appetite. However, the results from current studies remain inconclusive. The aim of the present study was to test whether a certain functional genetic variant (SNP rs16147) in the NP-Y promoter gene is associated with serum leptin levels and body fat distribution. Method: We genotyped and measured the serum leptin levels of the NP-Y rs16147 polymorphism in 1,097
\end{abstract}

Caucasian subjects in the context of a population-based, case-control multicenter study. We measured weight, height and waist circumference, from which we then calculated BMI and waist-to-hip ratio (WHR). Results: We found the CT-genotype of the SNP rs 16147 to be significantly associated with lower WHRs and higher serum leptin levels in women, compared to homozygote gene carriers. No association between rs16147, WHR and serum leptin levels was found in men. Conclusion: Our results provide evidence that the functionally relevant SNP in the NP-Y promoter gene affects body fat distribution and serum leptin levels in women, pointing towards possible behavioral effects of NPY in obesity.

Copyright $\odot 2013$ S. Karger AG, Basel

\section{KARGER}

E-Mail karger@karger.com

www.karger.com/anm (c) 2013 S. Karger AG, Basel

0250-6807/13/0624-0271\$38.00/0
Jochen Mutschler, MD

Department of Addictive Behavior and Addiction Medicine Central Institute of Mental Health, University of Heidelberg, Square J 5 DE-68159 Mannheim (Germany)

E-Mail jochen.mutschler@ puk.zh.ch 


\section{Introduction}

Obesity is a major health problem with extensive consequences not only for those it affects but also for society as a whole [1]. In particular, central obesity - which is measured using the waist-to-hip ratio (WHR) - is associated with increased risk of diabetes, depression, kidney disease, obesity-related cancers and death from cardiovascular disease [2-5]. However, the mechanisms and pathways underlying central obesity and regulation of body fat distribution are not completely understood. While the genetic risk factors [6] as well as the environmental factors [7-10] underlying obesity are still relatively poorly understood, a better understanding of the complex interactions between physical, endocrinological, genetic and molecular phenotypes is needed [11]. Recent evidence suggests that only around $50 \%$ of the variation between individuals in body weight has a genetic basis, but these effects are dominated by polygenetic environmental interactions that reflect many genetic influences affecting spontaneous physical activity, metabolic rate, endocrinological changes and appetite behavior [1]. There are a large number of hormones and neuropeptides involved in regulating the homeostasis of body weight, appetite and food intake. Current research has shown the leptin and neuropeptide-Y (NP-Y) systems to be two of the most interesting and important regulators of appetite and energy homeostasis [12, 13]. Since leptin, an anorexigenic peptide, is secreted by adipocytes in proportion to lipid reserves, serum leptin levels provide feedback about the body's fat stores [14]. Leptin is also involved in the long-term regulation of adiposity, and recent research has suggested that leptin diminishes food intake by signaling satiety in the hypothalamus [14]. In obese individuals, a leptin-resistance mechanism affects leptin's regulatory effect, which explains the positive correlation observed between serum leptin levels and body fat mass [15]. In contrast to leptin, NP-Y is an orexigenic neuropeptide, and it promotes food intake and helps reduce energy expenditure [16]. A recently published study found that changes of plasma levels of anti-NP-Y plasma immunoglobulins are relevant to altered appetite and body weight in patients with depressive disorder [17]. Findings from a recent study suggest that circulating leptin directly engages NP-Y neurons, thus regulating bodyweight homeostasis [18]. Furthermore, melatonin has recently been found to play a role in central appetite regulation by modulating the gene transcription of leptin and NP-Y [19]. Also, there is growing evidence that in addition to their roles regulating food intake and energy expenditure, both peptides (NP-Y and leptin) also closely interact with mesolimbic reward pathways [20,21]. Since the effects of food intake are self-reinforcing, there has been increased discussion recently as to whether severe obesity and addiction disorders share any common neuronal circuits $[5,22]$. Furthermore, gene variations in both systems (NP-Y and leptin) have been found to be associated with central obesity as well as numerous psychiatric conditions [14, 23-25]. Obesity is to an essential degree the consequence and measure of maladaptive eating behavior. Despite neurobiological processes controlling food intake, the interaction of genetic, psychological and endocrinological factors which thus constitute risk factors of weight gain and obesity are complex, but important to investigate [1]. Analysis of the candidate genes that regulate psychological and endocrinological pathways could lead to a better understanding of the pathophysiology of central obesity. To this end, we analyzed whether or not a certain functional genetic variant in the NP-Y-promoter gene (SNP rs16147) is associated with body fat distribution and serum leptin levels in an ethnically homogenous sample of healthy white subjects.

\section{Methods}

\section{Data Collection}

For the case-control association analysis, we analyzed data from a cohort investigating the phenotypes and genetics of nicotine dependence. Of our subjects, 466 were male, 631 were female (entire sample $\mathrm{n}=1,097$ ) and all were genotyped. Data were collected at seven recruitment centers located throughout Germany (Departments of Psychiatry at the Universities of Aachen, Berlin, Bonn, Duesseldorf, Erlangen, Mainz, and Mannheim) between 2007 and 2009. All participants were required to be of German origin and to speak German at a native-speaker level. Only ethnically German subjects were included. Details on the recruitment, testing procedures, inclusion/exclusion criteria and characterization of this multicenter study on nicotine dependence and smoking-related behavior have been published elsewhere [26, 27].

Prospective subjects' conformity to inclusion/exclusion criteria was assessed using a medical examination, a standardized psychiatric interview (SCID-I), questionnaires, drug screenings, alcohol testing and carbon monoxide measurement.

The present study was approved by the ethics committees of all participating centers. Subjects were included in the study only after they had given written, informed consent.

\section{Measures and Testing Procedures}

The testing sessions were subjected to a strict timetable and included a standardized $600 \mathrm{kcal}$ meal during a 1-hour lunch break taken at noon. The assessments started at 8:30 a.m. and lasted until 4:30 p.m. for all participants. The absence of psychiatric axis-I comorbidity was verified using the Structured Clinical Interview, which is based on DSM-IV criteria (American Psychiatric Asso- 
ciation, 2000). Bodyweight, BMI and waist-hip ratio (WHR) were assessed for all participating subjects according to standard procedures. BMI was calculated as body weight $(\mathrm{kg})$ divided by the square of height $(\mathrm{m})$.

\section{DNA Preparation and Genotyping}

Genotyping was performed at the Cologne Center for Genomics at the University of Cologne. DNA from fresh frozen EDTA blood was prepared using a Qiagen FlexiGene DNA Kit according to the manufacturer's instructions and normalized based on RNase $\mathrm{P}$ copy number measurement using the TaqMan RNase $\mathrm{P}$ assay from Applied Biosystems ${ }^{\circledR}$ (Foster City, Calif., USA). The SNP rs16147, a functional NP-Y promoter variant, was chosen to cover the functional expression of brain NP-Y. Genotyping was performed using SNP stream SNP genotyping assays. Genotyping call rates were $99 \%$. All laboratory procedures were carried out blind to case-control status.

\section{Hormonal Measures}

Blood samples were obtained between 2:00 and 4:30 p.m. by venipuncture, and were then anticoagulated with sodium EDTA ( $1 \mathrm{mg} / \mathrm{ml}$ whole blood) and immediately cooled on ice. Plasma was separated by centrifugation with $4,000 \mathrm{~g}$ and aliquots were frozen immediately and stored at $-80^{\circ} \mathrm{C}$ until analysis (maximum 6 months). The leptin analyses were performed at the Neurobiological Laboratory of the Department of Psychiatry at the University Hospital of Hamburg.

To measure serum leptin levels, we used a human leptin radioimmunoassay kit (Linco, St. Charlex, Mo., USA). The detection limit was $0.25 \mathrm{ng} / \mathrm{ml}$ of plasma; intra- and inter-assay coefficients of variation for 4.9 . and $15.7 \mathrm{ng} / \mathrm{ml}$ levels were below $8.5 \%$.

\section{Data Analysis}

Associations between genotype and gender as well as obesity and gender were evaluated using the $\chi^{2}$ test. The gender-specific risk of obesity is given in odds ratio and its confidence interval. Due to the fact that all three dependent variables (BMI, WHR and leptin) deviated from a normal distribution (Kolmogorov-Smirnov test for all three variables: $\mathrm{p}<0.001$ ), we performed nonparametric, Mann-Whitney tests in order to compare the influence of the genotype. The genotypes were divided into two groups: one for homozygotes (CC and TT) and another for heterozygotes (CT). Additionally, we calculated correlative associations using Pearson's correlations (two-tailed). All tested statistics indicating a $\mathrm{p}$ value of 0.05 or less were considered significant. We tested for deviation from Hardy-Weinberg equilibrium using Fisher's exact test. The data analysis was performed using SPSS Statistics, version 19.

\section{Results}

\section{Group Characteristics}

A total of 1,097 subjects were genotyped for SNP rs16147. This total sample was primarily female (631 female, 466 male), aged $34.7 \pm 12.8$ years. SNP rs 16147 did not deviate from Hardy-Weinberg equilibrium (TT $=$ 258, 23.5\%; CT $=561,51.1 \%$, and $\mathrm{CC}=278,25.3 \%$; $\mathrm{p}=$ $0.469)$. Genotype distributions for the study population
Table 1. Distribution of genotypes in women and men

\begin{tabular}{llll}
\hline rs16147 & CC & CT & TT \\
\hline Women & $143(22.7 \%)$ & $345(54.7 \%)$ & $143(22.7 \%)$ \\
Men & $135(29.0 \%)$ & $216(46.4 \%)$ & $115(24.7 \%)$ \\
\hline
\end{tabular}

(women and men) are presented in table 1. The study population's sociodemographic and clinical characteristics have been described in previous papers [27-29].

For the purposes of this study, obesity was defined as a BMI of 30 or greater. Of the participants, 120 had a BMI greater than 30 (10.9\% of the sample); broken down by gender, 57 of the women were obese (9\%) compared to 63 of the men (13.5\%). Obesity was unequally distributed between men and women $\left(\chi^{2}=5.578, p=0.018\right)$, with men having a higher probability of being obese compared to woman $(\mathrm{OR}=1.577,95 \% \mathrm{CI} 1.08-2.31)$.

The mean WHR for homozygote allele carriers was $0.834( \pm 0.955)$ compared to $0.819( \pm 0.909)$ for heterozygote allele carriers. The TT and CC genotypes of rs 16147 were significantly associated with an increased risk of higher WHRs in comparison to the CT genotype (MannWhitney $\mathrm{U}=108.760, \mathrm{p}=0.008$ ). This association seems to be gender specific, with homozygote (TT and CC; mean WHR $=0.795 \pm 0.083$ ) women having significantly higher WHR than heterozygote (CT; mean WHR $=0.773$ \pm 0.068 ) women (Mann-Whitney $U=33.730, p=0.001$ ). In men this comparison is not significant (Mann-Whitney $\mathrm{U}=22.424, \mathrm{p}=0.264$ ). However, comparisons of CC and TT alleles did not show any significant differences (Mann-Whitney $\mathrm{U}=5.877, \mathrm{p}=0.728$ ).

The mean BMI in women was $23.481( \pm 4.855)$, and in men it was $25.301( \pm 4.210)$. This difference was found to be significant (Mann-Whitney $U=187.575, \mathrm{p}<0.001$ ). However, the mean BMI's of homozygote allele carriers $(24.386 \pm 4.578)$ and heterozygote allele carriers (24.170 $\pm 4.805)$ did not differ significantly (Mann-Whitney $\mathrm{U}=$ 140.927, $\mathrm{p}=0.212$ ).

The mean serum leptin levels in homozygote allele carriers was $8.798 \pm 8.488 \mathrm{ng} / \mathrm{ml}$, compared to $9.669 \pm 9.155$ $\mathrm{ng} / \mathrm{ml}$ in heterozygote allele carriers, which indicates significantly higher serum leptin levels in heterozygote allele carriers (Mann-Whitney $U=152.908, p=0.025$ ). We found the highest serum leptin levels in heterozygote women $(12,516 \pm 10,091 \mathrm{ng} / \mathrm{ml})$, which were higher than both homozygote women $(11,626 \pm 8,695 \mathrm{ng} / \mathrm{ml})$ and homozygote men (homozygote: $5.509 \pm 6.928 \mathrm{ng} / \mathrm{ml}$; het- 


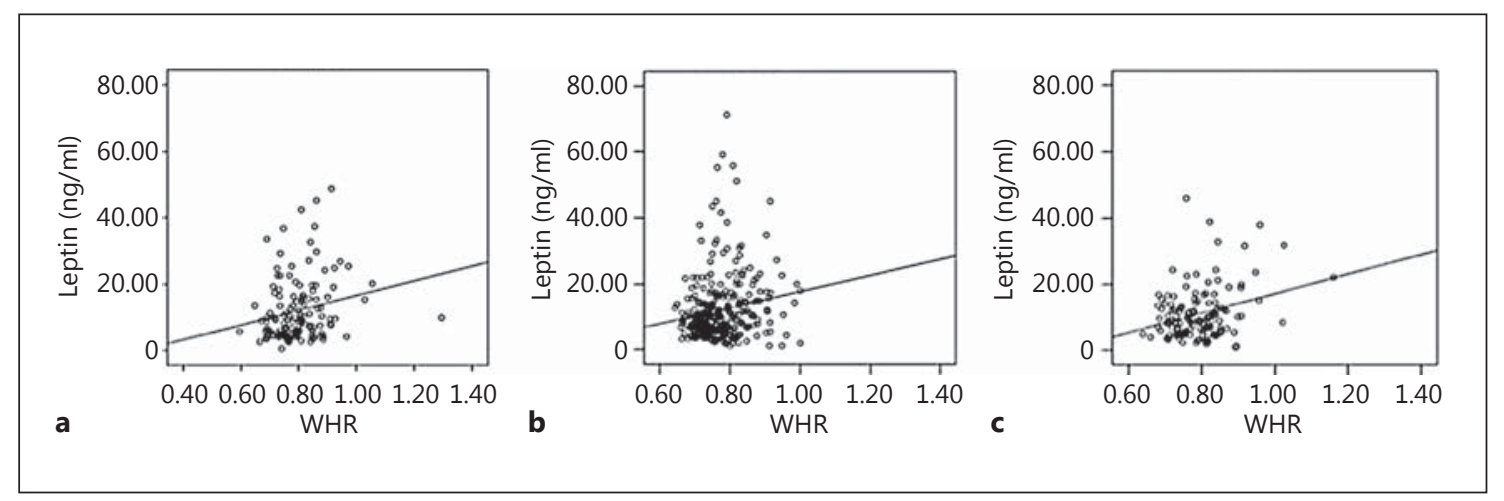

Fig. 1. All genotypes show significant correlation between serum leptin levels and WHR: genotype CC, $r=0.210$, $\mathrm{p}<0.017(\mathbf{a})$; genotype CT, $\mathrm{r}=0.166, \mathrm{p}=0.004(\mathbf{b})$; genotype TT, $\mathrm{r}=0.290, \mathrm{p}=0.001(\mathbf{c})$.

erozygote: $5.05 \pm 4.50725 \mathrm{ng} / \mathrm{ml})$. Serum leptin levels were $12.115( \pm 9.491) \mathrm{ng} / \mathrm{ml}$ in women, compared to $5.296( \pm 5.921) \mathrm{ng} / \mathrm{ml}$ in men (Mann-Whitney $\mathrm{U}=55.668$, $\mathrm{p}<0.001)$. However, all three genotypes showed significant correlations between serum leptin and WHR (fig. 1).

We conducted further series of correlation analyses, the results of which showed leptin to be significantly associated with BMI $(\mathrm{r}=0.474, \mathrm{p}<0.001)$. In addition, we found serum leptin to be positively correlated with both heart rate $(\mathrm{r}=0.061, \mathrm{p}=0.049)$ and blood pressure (diastolic: $\mathrm{r}=0.106, \mathrm{p}=0.001$; systolic: $\mathrm{r}=0.076, \mathrm{p}=0.015$ ). We also found BMI to be significantly correlated with WHR $(\mathrm{r}=0.498, \mathrm{p}<0.001)$.

We did not observe significant differences between the different alleles of the SNP rs16147 concerning levels of cortisol, ACTH, orexin and cotinin (data not shown).

\section{Discussion}

The novel finding of the present study is that the single nucleotide polymorphism rs 16147 , located in the NP-Y gene promoter, is significantly associated with both WHR and serum leptin concentrations. These associations were sex specific, applying only to women. Our main result is not surprising, since various NP-Y gene variants have recently been found to be associated with obesity [30]. However, the evidence supporting the association between obesity and polymorphisms of the NP-Y gene has been inconsistent. In a large study, the functionally relevant NP-Y SNP rs16147 was not found to be associated with obesity, despite other SNPs covering the NP-Y gene having been found to be associated with obesity (rs17149106, rs16139) [30]. Our study confirmed this re- sult and also found no association between BMI and rs16147. However, we did find rs 16147 to be associated with the distribution of the body fat (central obesity). Furthermore, our finding is sex specific. Sexual dimorphism in human body composition is already well known and has been recently described. Compared to women, men are taller, they have lower overall fat mass and their fat distribution, total lean mass and bone mineral mass are also different [31]. Previous studies support our main finding, reporting that the genetic variance for WHR is significantly higher in women than in men [32]. The NP-Y gene thus accounts not only for BMI, as previous studies had suggested. Our results demonstrate that the NP-Y gene also accounts for body fat distribution measured with WHR (an important obesity-related trait), and they also reveal a gene-by-sex interaction.

In a recently published paper by our group using the same database, it could be demonstrated that smokers with a pathological eating behavior show an impaired neuroendocrine regulation of appetite and are prone to experience higher levels of stress and negative affectivity [26]. Altered psychological states (e.g. depression, stress) have been repeatedly associated with impaired neurobiological processes controlling food intake [11, 33-35]. Leptin is an important endocrinological mediator that not only controls for eating behavior, but also acts as an important mediator in stress reactions and depressed mood [36]. One finding of our study is that serum leptin levels are positively correlated with BMI, blood pressure, heart rate and WHR, a finding which has already been reported repeatedly [37]. We found significantly higher serum leptin levels in women with the CT allele compared to female CC- and TT-allele carriers (rs16147). Previous studies had already found leptin levels to be higher in fe- 
males than males if leptin levels are expressed as a percentage of body fat $[38,39]$. Our result is surprising since most previous studies had found positive associations between leptin and BMI/WHR [40, 41]. However, increased leptin levels have not always been found to be associated with increased bodyweight $[42,43]$. As a restriction, it should be noted that in our study we assessed serum leptin levels cross-sectionally, and thus we could not discriminate between acute and chronic hyperleptinemia, although doing so is important for assessing leptin's longterm biological effects.

Taken together, our results suggest that the NP-Y system is involved in body fat distribution in women. We found that individuals carrying the risk genotypes TT and CC of rs16147, which have been found to be associated with altered NP-Y levels in earlier studies [44-46], have both significantly lower serum leptin levels and a higher individual vulnerability to increased WHR. These results were sex specific, implying additional risk factors contributing to the complex phenotype of obesity and WHR. Our study does have some limitations. Firstly, the study findings are not generalizable to all people suffering from obesity as the primary goal of the study was not to study obesity but to investigate tobacco dependence in smokers and nonsmokers. Secondly, we did not investigate whether rs16147 influences NP-Y and leptin expression directly or indirectly, or whether it acts through other pathways - a question that should be addressed in future studies. Furthermore, our study population lacked ethnic diversity, as the analysis was limited to individuals of German ancestry as a means of avoiding the effects of population stratification. For this reason, the study findings may not apply to populations of non-German descent. Finally, there are many nongenetic factors that influence WHR and leptin levels, including circadian rhythms, psychological factors, sex, addiction, as well as other hormones like insulin and cortisol, none of which were taken to account in the present study. The strengths of our analysis include that we found a so far unknown association in the NP-Y gene promoter that may constitute a genetic risk factor for elevated WHR in woman. However, further studies are needed to replicate our preliminary findings.

To our knowledge, this is the first study showing a gene-by-sex interaction with an association between rs 16147, serum leptin and WHR. However, the pathogenesis of obesity and obesity-related traits is complex and involves both genetic and environmental factors. Therefore, additional studies looking at different genes, exact (endo-)phenotypes and environmental factors would be useful contributions to this field.

\section{Acknowledgments}

We would like to thank Carsten Wied for his assistance with the data collection.

Funding for this study was provided within the framework of the German Priority Program SPP1226 'Nicotine - Molecular and Physiological Mechanisms in CNS' by grants from the German Research Foundation (DFG KI 782/5-1 and Wi1316/9-1).

\section{Disclosure Statement}

All authors have no conflict of interest.

\section{References}

1 Haslam DW, James WP: Obesity. Lancet 2005;366:1197-1209.

2 Canoy D: Distribution of body fat and risk of coronary heart disease in men and women. Curr Opin Cardiol 2008;23:591-598.

3 Carey VJ, Walters EE, Colditz GA, Solomon CG, Willett WC, Rosner BA, Speizer FE, Manson JE: Body fat distribution and risk of non-insulin-dependent diabetes mellitus in women. The Nurses' Health Study. Am J Epidemiol 1997;145:614-619.

4 Pischon T, Boeing H, Hoffmann K, et al: General and abdominal adiposity and risk of death in Europe. N Engl J Med 2008;359: 2105-2120.
5 Volkow ND, Wang GJ, Fowler JS, Tomasi D, Baler R: Food and drug reward: overlapping circuits in human obesity and addiction. Curr Top Behav Neurosci 2012;11:1-24.

6 Barsh GS, Farooqi IS, O'Rahilly S: Genetics of body-weight regulation. Nature 2000;404: 644-651.

7 Ludwig J, Sanbonmatsu L, Gennetian L, Adam E, Duncan GJ, Katz LF, Kessler RC, Kling JR, Lindau ST, Whitaker RC, McDade TW: Neighborhoods, obesity, and diabetes - a randomized social experiment. N Engl J Med 2011;365:1509-1519.

8 Schroeder M, Moran TH, Weller A: Attenuation of obesity by early-life food restriction in genetically hyperphagic male OLETF rats: peripheral mechanisms. Horm Behav 2010;57: 455-462.
9 Schroeder M, Shbiro L, Gelber V, Weller A: Post-weaning voluntary exercise exerts longterm moderation of adiposity in males but not in females in an animal model of early-onset obesity. Horm Behav 2010;57:496-505.

10 Viveros MP, Llorente R, Diaz F, Romero-Zerbo SY, Bermudez-Silva FJ, Rodriguez de Fonseca F, Argente J, Chowen JA: Maternal deprivation has sexually dimorphic long-term effects on hypothalamic cell-turnover, body weight and circulating hormone levels. Horm Behav 2010;58:808-819.

11 Mutschler J, Kiefer F: The natriuretic peptide system as a possible therapeutic target for stress-induced obesity. Med Hypothese 2011; 76:388-390. 
12 Abizaid A, Gao Q, Horvath TL: Thoughts for food: brain mechanisms and peripheral energy balance. Neuron 2006;51:691-702.

13 Gao Q, Horvath TL: Neurobiology of feeding and energy expenditure. Annu Rev Neurosci 2007;30:367-398

14 Paracchini V, Pedotti P, Taioli E: Genetics of leptin and obesity: a HuGE review. Am J Epidemiol 2005;162:101-114.

15 Considine RV, Sinha MK, Heiman ML, Kriauciunas A, Stephens TW, Nyce MR, Ohannesian JP, Marco CC, McKee LJ, Bauer TL, et al: Serum immunoreactive-leptin concentrations in normal-weight and obese humans. N Engl J Med 1996;334:292-295.

16 Yulyaningsih E, Zhang L, Herzog H, Sainsbury A: NPY receptors as potential targets for anti-obesity drug development. Br J Pharmacol 2011;163:1170-1202.

17 Garcia FD, Coquerel Q, do Rego JC, Cravezic A, Bole-Feysot C, Kiive E, Dechelotte P, Harro J, Fetissov SO: Anti-neuropeptide Y plasma immunoglobulins in relation to mood and appetite in depressive disorder. Psychoneuroendocrinology 2012;37:1457-1467.

18 Elias CF, Aschkenasi C, Lee C, Kelly J, Ahima RS, Bjorbaek C, Flier JS, Saper CB, Elmquist JK: Leptin differentially regulates NPY and POMC neurons projecting to the lateral hypothalamic area. Neuron 1999;23:775786.

19 Piccinetti CC, Migliarini B, Olivotto I, Coletti G, Amici A, Carnevali O: Appetite regulation: the central role of melatonin in Danio rerio. Horm Behav 2010;58:780-785.

20 Grosshans M, Loeber S, Kiefer F: Implications from addiction research towards the understanding and treatment of obesity. Addict Biol 2011;16:189-198.

21 Shohat-Ophir G, Kaun KR, Azanchi R, Heberlein U: Sexual deprivation increases ethanol intake in Drosophila. Science 2012;335: 1351-1355.

22 Ziauddeen H, Faroogi IS, Fletcher PC: Obesity and the brain: how convincing is the addiction model? Nat Rev Neurosci 2012;14: 279-286.

23 Hafner S, Baumert J, Emeny RT, Lacruz ME, Thorand B, Herder C, Koenig W, Rupprecht $\mathrm{R}$, Ladwig KH: Sleep disturbances and depressed mood: a harmful combination associated with increased leptin levels in women with normal weight. Biol Psychol 2012;89: 163-169.

24 Kiefer F, Jahn H, Kellner M, Naber D, Wiedemann K: Leptin as a possible modulator of craving for alcohol. Arch Gen Psychiatry 2001;58:509-510.

25 von der Goltz C, Koopmann A, Dinter C, Richter A, Rockenbach C, Grosshans M, Nakovics H, Wiedemann K, Mann K, Winterer G, Kiefer F: Orexin and leptin are associated with nicotine craving: a link between smoking, appetite and reward. Psychoneuroendocrinology 2010;35:570-577.

26 Koopmann A, Dinter C, Grosshans M, von der Goltz C, Hentschel R, Dahmen N, Gallinat
J, Wagner M, Grunder G, Thurauf N, Wienker T, Brinkmeyer J, Mobascher A, Spreckelmeyer KN, Clepce M, de Millas W, Wiedemann K, Winterer G, Kiefer F: Psychological and hormonal features of smokers at risk to gain weight after smoking cessation - results of a multicenter study. Horm Behav 2011;60: $58-64$.

27 Lindenberg A, Brinkmeyer J, Dahmen N, Gallinat J, de Millas W, Mobascher A, Wagner M, Schulze-Rauschenbach S, Grunder G, Spreckelmeyer KN, Clepce M, Thurauf N, von der Goltz C, Kiefer F, Steffens M, Holler D, DiazLacava A, Wienker T, Winterer G: The German multi-centre study on smoking-related behavior - description of a population-based case-control study. Addict Biol 2011;16:638653.

28 Mutschler J, Abbruzzese E, von der Goltz C, Dinter C, Mobascher A, Thiele H, Diaz-Lacava A, Dahmen N, Gallinat J, Majic T, Petrovsky N, Thuerauf N, Kornhuber J, Gründer G, Brinkmeyer J, Wienker T, Wagner M, Winterer G, Kiefer F: Genetic variation in the neuropeptide $\mathrm{Y}$ gene promoter is associated with increased risk of tobacco smoking. Eur Addict Res 2012;18:246-252.

29 Vollstadt-Klein S, Loeber S, Winter S, Lemenager T, von der Goltz C, Dinter C, Koopmann A, Wied C, Winterer G, Kiefer F: Attention shift towards smoking cues relates to severity of dependence, smoking behavior and breath carbon monoxide. Eur Addict Res 2011;17:217-224.

30 Yeung EH, Zhang C, Chen J, Bowers $\mathrm{K}, \mathrm{Hu}$ FB, Kang G, Qi L: Polymorphisms in the neuropeptide y gene and the risk of obesity: findings from two prospective cohorts. J Clin Endocrinol Metab 2011;96:E2055-E2062.

31 Zillikens MC, Yazdanpanah M, Pardo LM, Rivadeneira F, Aulchenko YS, Oostra BA, Uitterlinden AG, Pols HA, van Duijn CM: Sex-specific genetic effects influence variation in body composition. Diabetologia 2008;51: 2233-2241.

32 Heid IM, Jackson AU, Randall JC, et al: Metaanalysis identifies 13 new loci associated with waist-hip ratio and reveals sexual dimorphism in the genetic basis of fat distribution. Nat Genet 2010;42:949-960.

33 Abildgaard A, Solskov L, Volke V, Harvey $\mathrm{BH}$, Lund S, Wegener G: A high-fat diet exacerbates depressive-like behavior in the Flinders Sensitive Line (FSL) rat, a genetic model of depression. Psychoneuroendocrinology 2011;36:623-633.

34 Daubenmier J, Lin J, Blackburn E, Hecht FM, Kristeller J, Maninger N, Kuwata M, Bacchetti P, Havel PJ, Epel E: Changes in stress, eating, and metabolic factors are related to changes in telomerase activity in a randomized mindfulness intervention pilot study. Psychoneuroendocrinology 2012;37:917928.

35 Ginty AT, Phillips AC, Higgs S, Heaney JL, Carroll D: Disordered eating behaviour is associated with blunted cortisol and cardiovas- cular reactions to acute psychological stress. Psychoneuroendocrinology 2012;37:715724

36 Hafner S, Zierer A, Emeny RT, Thorand B, Herder C, Koenig W, Rupprecht R, Ladwig $\mathrm{KH}$ : Social isolation and depressed mood are associated with elevated serum leptin levels in men but not in women. Psychoneuroendocrinology 2011;36:200-209.

37 Beltowski J: Role of leptin in blood pressure regulation and arterial hypertension. J Hypertens 2006;24:789-801.

38 Beumer W, Drexhage RC, De Wit H, Versnel MA, Drexhage HA, Cohen D: Increased level of serum cytokines, chemokines and adipokines in patients with schizophrenia is associated with disease and metabolic syndrome. Psychoneuroendocrinology 2012;37:19011911.

39 Martin LJ, Mahaney MC, Almasy L, MacCluer JW, Blangero J, Jaquish CE, Comuzzie AG: Leptin's sexual dimorphism results from genotype by sex interactions mediated by testosterone. Obes Res 2002;10:14-21.

40 Havel PJ: Role of adipose tissue in bodyweight regulation: mechanisms regulating leptin production and energy balance. Proc Nutr Soc 2000;59:359-371.

41 Plonka M, Toton-Morys A, Adamski P, Suder A, Bielanski W, Dobrzanska MJ, Kaminska A, Piorecka B, Glodzik J: Association of the physical activity with leptin blood serum level, body mass indices and obesity in schoolgirls. J Physiol Pharmacol 2011;62:647-656.

42 Farooqi IS, Keogh JM, Kamath S, Jones S, Gibson WT, Trussell R, Jebb SA, Lip GY, O'Rahilly S: Partial leptin deficiency and human adiposity. Nature 2001;414:34-35.

43 Ravussin E, Pratley RE, Maffei M, Wang H, Friedman JM, Bennett PH, Bogardus C: Relatively low plasma leptin concentrations precede weight gain in Pima Indians. Nat Med 1997;3:238-240.

44 Sommer WH, Lidstrom J, Sun H, Passer D, Eskay R, Parker SC, Witt SH, Zimmermann US, Nieratschker V, Rietschel M, Margulies EH, Palkovits M, Laucht M, Heilig M: Human NPY promoter variation $r$ ss $16147: \mathrm{T}>\mathrm{C}$ as a moderator of prefrontal NPY gene expression and negative affect. Hum Mutat 2010; 31:E1594-E1608

45 Witt SH, Buchmann AF, Blomeyer D, Nieratschker V, Treutlein J, Esser G, Schmidt $\mathrm{MH}$, Bidlingmaier $\mathrm{M}$, Wiedemann $\mathrm{K}$, Riestschel M, Laucht M, Wust S, Zimmermann US: An interaction between a neuropeptide $Y$ gene polymorphism and early adversity modulates endocrine stress responses. Psychoneuroendocrinology 2011;36:1010-1020.

46 Zhou Z, Zhu G, Hariri AR, Enoch MA, Scott D, Sinha R, Virkkunen M, Mash DC, Lipsky RH, Hu XZ, Hodgkinson CA, Xu K, Buzas B, Yuan Q, Shen PH, Ferrell RE, Manuck SB, Brown SM, Hauger RL, Stohler CS, Zubieta JK, Goldman D: Genetic variation in human NPY expression affects stress response and emotion. Nature 2008;452:997-1001. 